\title{
Complicações iniciais do uso de dois microceratótomos automatizados
}

\author{
Initialcomplicationsof two automated microkeratomes
}

\author{
Monica do Carmo Passos ${ }^{1}$ \\ Ricardo Takahashi ${ }^{1}$ \\ Edson S. Mori ${ }^{1,2}$ \\ César K.Suzuki ${ }^{1}$ \\ Paulo Schor ${ }^{1,2}$
}

\section{RESUMO}

Objetivo: Descrever as complicações per e pós-operatórias ocorridas durante o uso inicial de dois microceratótomos automatizados na realização de LASIK. Métodos: Estudo retrospectivo das primeiras cirurgias realizadas com dois microceratótomos automatizados, sendo 70 olhos de 54 pacientes utilizando o microceratótomo da Chiron ${ }^{\circledR}$ modelo Automated Corneal Shaper (ACS), no período de abril de 1997 a abril de 1998 e 100 olhos de 82 pacientes com o microceratótomo automatizado Moria ${ }^{\circledR}$ Carriazo-Barraquer (CB), durante o período de fevereiro de 1999 a junho de 1999. A fotoablação foi realizada com excimer laser de fluoreto de argônio de $193 \mathrm{~nm}$ da Summit modelo Apex Plus ${ }^{\circledR}$. Foram avaliadas as complicações per e pós-operatórias até um mês de seguimento. Resultados: A fotoablação não foi realizada em 3 casos (4,3\%) usando-se o microceratótomo ACS e em 1 caso (1\%) usando o microceratótomo $\mathrm{CB}$. As complicações mais freqüentemente encontradas com o ACS foram: falha no retorno automatizado do microceratótomo (7,1\%), ceratectomia parcial ("flap" incompleto): $4,3 \%$, presença de dobras estromais (14,3\%), desepitelização central $(4,3 \%)$ e crescimento epitelial na interface $(4,3 \%)$. Já com o CB, foram encontrados: "flap" descentralizado (3\%), desepitelização central (5\%), dobras estromais $(28 \%)$ e síndrome das Areias de Sahara (6\%). Conclusões: O uso inicial de ambos microceratótomos foi relacionado a considerável índice de complicações per e pós-operatórias, não levando necessariamente à perda de visão. Maior conhecimento clínico das alterações ocorridas com o uso destes instrumentos, bem como maior experiência na sua utilização podem diminuir a ocorrência de complicações.

Descritores: Ceratomileuse assistida por excimer laser in situ/complicações; Ceratectomia fotorrefrativa por excimer laser; Cirurgia a laser; Microcirurgia

\section{INTRODUÇÃO}

A técnica da ceratectomia fotorrefrativa associada à ceratectomia lamelar pediculada (LASIK) para correção de miopia, astigmatismo e hipermetropia tem sido amplamente utilizada e divulgada nos dias de hoje. Este procedimento é utilizado com uma segurança cada vez maior, não só no que diz respeito à técnica cirúrgica ${ }^{(1-2)}$ como também à previsibilidade dos resultados, levando a uma melhora da acuidade visual não corrigida no período pós-operatório ${ }^{(3-4)}$.

A cirurgia refrativa contemporânea teve início com José I. Barraquer em 1964. A partir daí foram desenvolvidos vários instrumentais cirúrgicos até chegarmos aos aparelhos de fotoablação e microceratótomos disponíveis no mercado, com previsibilidade e segurança muito maiores. 
Atualmente a técnica cirúrgica do LASIK consiste na realização de uma ceratectomia lamelar pediculada através de um microceratótomo, que pode ser manual ou automatizado, realização da fotoablação corneana através de um aparelho de excimer laser de fluoreto de argônio emitindo radiação ultravioleta e comprimento de onda de $193 \mathrm{~nm}$. O mecanismo de ablação consiste em remover tecido do estroma corneano por um mecanismo de fotovaporização ${ }^{(3)}$.

Nesta cirurgia podem ocorrer complicações relacionadas ao uso dos diversos tipos de microceratótomos utilizados na realização da ceratectomia lamelar pediculada ${ }^{(5-8)}$, como "flaps" irregulares, incompletos ou totais, dobras estromais, Síndrome das Areias de Sahara e infecção.

A rápida recuperação visual, a satisfação dos pacientes, a previsibilidade nas altas ametropias e a estabilidade refracional têm sido fatores decisivos na escolha desta técnica cirúrgica, pelo cirurgião. No entanto, existe uma curva de aprendizado até que se possa realizar corretamente a ceratotomia lamelar ${ }^{(1)}$. O treinamento correto é fundamental para a diminuição de complicações ${ }^{(3)}$.

O objetivo deste trabalho é descrever as principais complicações iniciais ocorridas com o uso de dois microceratótomos automatizados na realização da cirurgia de LASIK em um serviço universitário.

\section{MÉTODOS}

Foi realizado um estudo retrospectivo de 70 olhos de 54 pacientes e 100 olhos de 82 pacientes submetidos a LASIK usando os microceratótomos Automated Corneal Shaper ${ }^{\circledR}$ ou ACS (Chiron) e Carriazo-Barraquer ${ }^{\circledR}$ ou CB (Moria) de abril de 1997 a abril de 1998 e de fevereiro de 1999 a junho de 1999 , respectivamente. A espessura da ceratotomia nos casos operados com o microceratótomo modelo ACS foi 130 ou 160 micra dependendo da paquimetria per-operatória. A foto-ablação foi realizada com "excimer laser" de fluoreto de argônio de $193 \mathrm{~nm}$ da Summit modelo Apex Plus ${ }^{\circledR}$.

Foram avaliadas e descritas as principais complicações ocorridas com o uso destes aparelhos nos períodos intraoperatório e pós-operatório imediato (15 minutos após a cirurgia) e pós-operatório recente (até um mês).

\section{RESULTADOS}

Foram observadas 11 complicações intra-operatórias (16\%) utilizando-se o microceratótomo ACS e 23 (23\%) utilizando-se o microceratótomo $\mathrm{CB}$, sendo que a fotoablação não foi realizada em $3(4,3 \%)$ e $1(1 \%)$ casos respectivamente.

Usando o ACS ocorreram 5 casos $(7,1 \%)$ nos quais houve falha no retorno automatizado do microceratótomo necessitando retorno manual do mesmo após ceratotomia regular; 1 caso $(1,4 \%)$ de ceratectomia total, 1 caso $(1,4 \%)$ de ceratectomia dupla, 3 casos $(4,3 \%)$ de ceratectomia parcial e 1 caso $(1,4 \%)$ de ceratectomia total.
Usando o CB, em 14 casos (14\%) houve a necessidade de realizar-se o retorno manual do microceratótomo após ceratectomia regular. Ocorreram também 3 casos (3\%) que apresentaram "flap" descentralizado, 5 casos (5\%) com desepitelização central e 1 caso (1\%) de ceratectomia parcial (Gráfico 1).

Até uma semana de pós-operatório foram observadas dobras com o uso de ambos microceratótomos. Ocorreram 3 casos $(4,3 \%)$ de dobras com o ACS sendo que em 2 (66,6\% dos casos de dobras) havia sido utilizado "flap" com 130 micra de espessura, e 28 casos (28\%) com o CB. Além das dobras, com o uso deste microceratótomo (CB) ocorreram também 6 casos (6\%) de Síndrome de Sahara, 1 caso (1\%) de deslocamento do retalho e 1 caso (1\%) de infecção. Já com o outro aparelho (ACS), constatamos neste período 3 casos $(4,3 \%)$ de desepitelização central; conforme exposto no gráfico 2 .

Os casos de Síndrome das Areias de Sahara apresentaram boa evolução após a introdução de corticóide tópico em altas doses. Esta intercorrência não interferiu na acuidade visual final destes pacientes.

O paciente que apresentou infecção no pós-operatório evoluiu com embaçamento visual (acuidade visual $=20 / 50$ ), dor, hiperemia conjuntival e epífora no terceiro dia após a cirurgia. Após instituição do tratamento específico houve melhora significativa do quadro e após 3 meses de cirurgia o paciente apresentava acuidade visual de 20/25, com refração sob cicloplegia de $+0,50 \mathrm{DE}$.

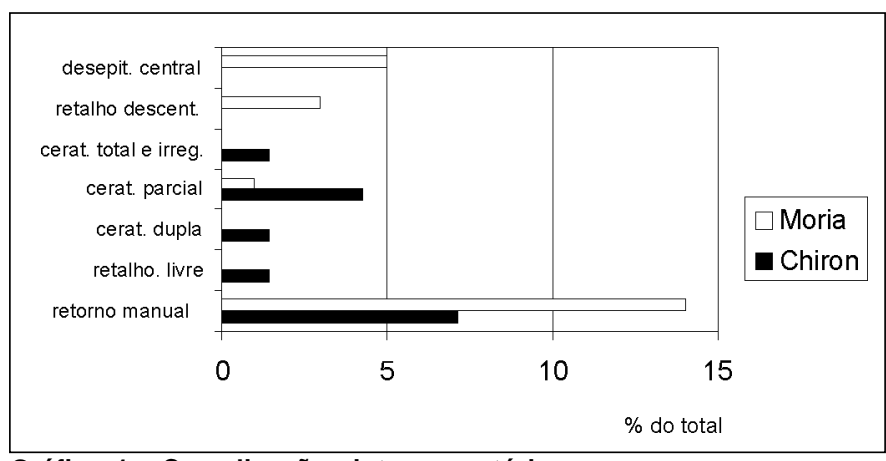

Gráfico 1 - Complicações intra-operatórias

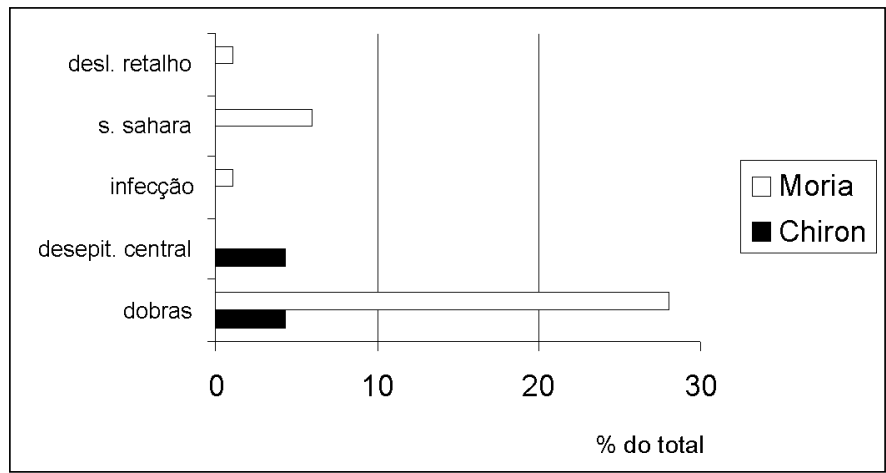

Gráfico 2 - Complicações pós-operatório (até 1 semana) 
Com 1 mês de pós-operatório foram observados, nos pacientes operados com o microceratótomo ACS (Chiron), mais 7 casos $(10 \%)$ de dobras e 3 casos $(4,3 \%)$ de crescimento epitelial na interface. Nos pacientes operados com o microceratótomo CB (Moria), encontramos 2 casos (2\%) de crescimento epitelial na interface (Gráfico 3).

O gráfico 4 mostra o total de complicações pós-operatórias acumuladas até 1 mês, excluindo-se aquelas que ocorreram durante a cirurgia (intra-operatório).

Com isso, obtivemos um total de 16 complicações $(23 \%$ dos pacientes operados) até 1 mês de seguimento utilizandose o microceratótomo ACS e 37 (37\% dos pacientes operados) utilizando-se o microceratótomo CB (Gráfico 4).

Além disso, quando analisamos as complicações ocorridas durante a cirurgia (intra-operatório) e até o seguimento de um mês após a intervenção, obtivemos um total de 27 complicações (39\%) com o uso do microceratótomo da Chiron (ACS) e $60(60 \%)$ com o uso do microceratótomo da Moria (CB).

\section{DISCUSSÃO}

Neste estudo foi encontrado um índice elevado de complicações intra e pós-operatórias (até um mês de seguimento) relacionadas aos microceratótomos utilizados. É importante salientar que foram envolvidos no trabalho vários cirurgiões

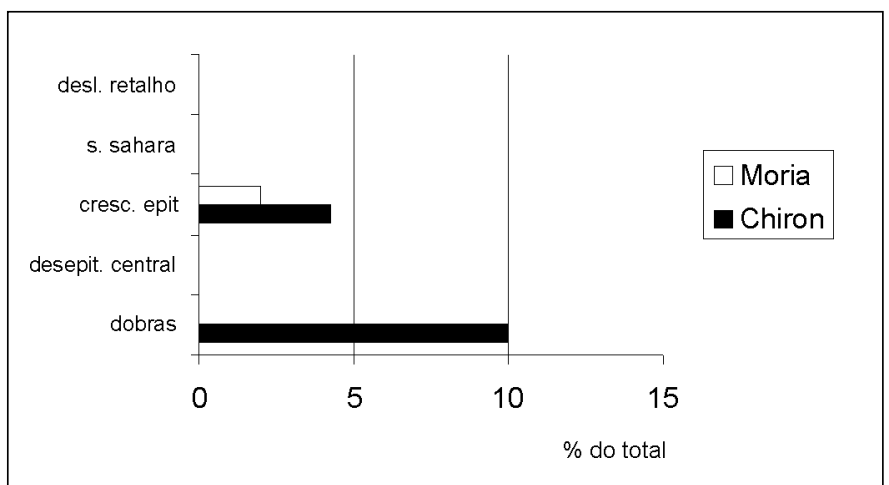

Gráfico 3 - Complicações pós-operatórias adicionais (até 1 mês)

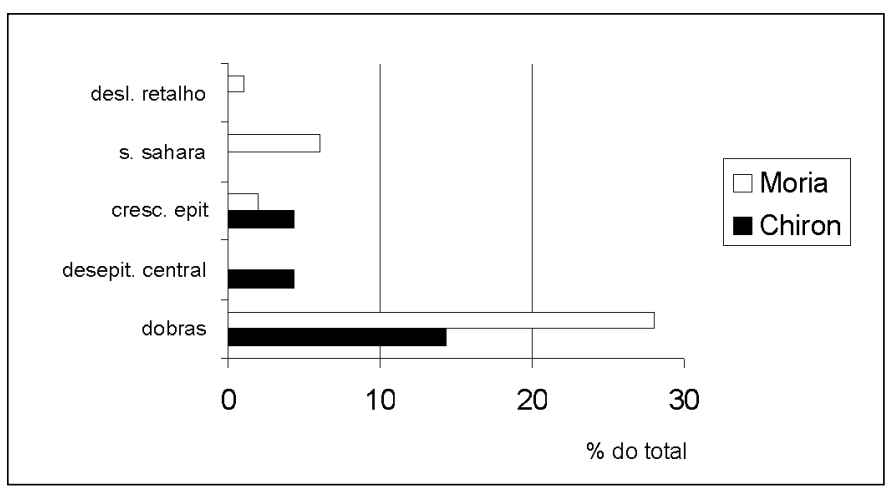

Gráfico 4 - Complicações pós-operatórias acumuladas (até 1 mês) em fase inicial de aprendizado tanto da utilização do laser quanto do microceratótomo, sempre sob supervisão de cirurgiões mais experientes. Isto pode ter contribuído para aumentar o número de intercorrências. A maioria das complicações ocorridas (retorno manual do microceratótomo, desepitelização central, dobras estromais que não interferiam na acuidade visual) foram facilmente contornadas não levando a prejuízo no resultado final da cirurgia. As complicações ocorreram com maior freqüência no início da utilização dos microceratótomos ${ }^{(3)}$ e estudos têm demonstrado que à medida em que há familiarização do cirurgião com estes instrumentos, o índice de complicações diminui consideravelmente ${ }^{(1,6)}$.

As complicações intra-operatórias mais freqüentemente encontradas com o ACS foram: falha no retorno automatizado do microceratótomo, ceratectomias total, dupla e parcial. Já com o CB foram: necessidade de realização de retorno manual do microceratótomo, retalho descentralizado, desepitelização central e ceratectomia parcial.

A necessidade de utilização manual do microceratótomo pode ocorrer pois a integração da oscilação lateral da lâmina e do deslocamento da cabeça do aparelho é conseguido por engrenagem interna acionada por motor elétrico. Para adequação no espaço e ergonomia, tal motor tem potência reduzida e revoluções na casa das 8 mil rpm. Por essas limitações há uma fragilidade inerente, que obriga a lubrificação constante e troca de instrumentos internos regularmente. Tais considerações são exemplificadas na alta freqüência que os motores, mesmo os novos, apresentaram de falhas em seu funcionamento. Outro fator importante é o acoplamento da cabeça ao trilho guia. Se for muito justo haver atrito demasiado e falha no avanço. Os problemas de propulsão têm sido minimizados com o uso de ar ao invés de eletricidade, e tais motores turbinados são mais potentes e promovem mais rotações. Por outro lado há nesses casos o desacoplamento do avanço da cabeça e da oscilação da lâmina (esta automatizada), obrigando o cirurgião ao avanço manual que carrega consigo outra curva de aprendizado.

Em relação aos problemas encontrados no corte, como cortes duplos ou irregulares, o estado da lâmina pode ser responsável pelo efeito. Nos microceratótomos disponíveis, as lâminas encontram-se expostas e sujeitas a toques, que mesmo sutis, podem danificar seu corte, e levar a imperfeições. A proteção das lâminas deveria ser motivo de preocupação, fabricantes.

As ceratectomias totais (retalhos livres) ocorrem quando as córneas são demasiadamente planas, e a área de aplanamento muito pequena. Aparelhos com anéis de ajuste, como o $\mathrm{CB}$, tendem a diminuir tal risco.

As ceratectomias parciais se diferenciam das irregulares, pois na última houve o corte até a parada do aparelho (até o fim do avanço), e nas primeiras não houve o avanço pleno. Isso ocorre quer pela inexperiência do cirurgião que julga já haver acabado o avanço e inicia o retrocesso antes de seu final, ou por obstruções no trajeto, que mecanicamente impe- 
dem o avanço total. Em ambos os casos a intervenção humana diminui os riscos, quer seja aguardando até que o aparelho chegue até o final do curso, ou se assegurando que o trilho esteja desimpedido de cílios, blefarostato, pálpebras ou "sterildrape" antes do início do corte.

As descentralizações são evitadas com o deslocamento ligeiramente superior (nos microceratótomos verticais), e nasal (em todos os casos). Isso porque a pupila em geral se apresenta mais nasal. As desepitelizações centrais são causadas por fraca aderência do epitélio à membrana basal, ou por demasiado atrito durante a passagem do aplanador sobre a córnea. Nas duas situações, a diminuição do atrito com lubrificação prévia ao corte minimiza riscos, e o até o uso de medicamentos fluidos como o colírio Alfagan ${ }^{\circledR}$ foram preconizados. Nossa rotina é a de irrigar a superfície da córnea com soro fisiológico imediatamente antes do corte.

Na primeira semana de pós-operatório ocorreram complicações como: presença de dobras com ambos os microceratótomos, desepitelização central com o uso do ACS, Síndrome das Areias do Sahara, deslocamento do retalho e infecção com o uso do CB.

Síndrome das Areias do Sahara foi encontrado em 6 casos (6\%) operados com o microceratótomo $\mathrm{CB}$ e em nenhum caso operado com o microceratótomo ACS. Tal complicação tem sido descrita como uma inflamação da interface que pode estar relacionada a diversos fatores como maior dificuldade na limpeza da lâmina e da cabeça do microceratótomo, diâmetro e espessura lamelares maiores, cabeça vertical, instrumental novo com uma menor familiarização no seu manuseio ${ }^{(8)}$.

A presença de infecção foi evidenciada e confirmada em apenas 1 caso ( $1 \%$ ) operado com o microceratótomo da Moria, de toda a série estudada. O microorganismo evidenciado no exame microbiológico foi o $S$. Aureus. O diagnóstico e tratamento precoces contribuiram para uma boa evolução do processo. Outros casos de ceratite infecciosa pós LASIK descritos na literatura que tiveram diagnóstico e tratamento precoces também tiveram evolução satisfatória ${ }^{(9-10)}$.

Até o primeiro mês de pós-operatório evidenciamos um aumento de $10 \%$ (7 casos) no número de dobras encontradas nos pacientes que haviam sido operados com o microceratótomo da Chiron, bem como a presença de crescimento epitelial na interface em 3 pacientes (4,3\%) operados com o microceratótomo da Chiron $\left(\mathrm{ACS}^{\circledR}\right)$ e em 2 pacientes $(2 \%)$ operados com o microceratótomo da Moria $\left(\mathrm{CB}^{\circledR}\right)$. Tal fato pode ser devido à diminuição do edema existente no pós-operatório imediato, permitindo então a melhor observação de detalhes, como as dobras. A epitelização de interface tem sido pouco descrita na literatura e se relaciona a manipulação excessiva do retalho no ato operatório, com eventual contato direto (por toque) ou indireto (por células soltas) do epitélio com o estroma subjacente. O levantamento do "flap" e a limpeza da interface deve ser realizada quando há sofrimento do estroma anterior, ou alteração na topografia corneana com conseqüências ópticas.

Outros trabalhos também demonstraram complicações se- melhantes àquelas encontradas no nosso estudo porém com índices menores, como é o caso dos trabalhos realizados por Gimbel e al. ${ }^{(1)}$ e por Lin e al. ${ }^{(6)}$ em que foram analisados $1000 \mathrm{e}$ 1019 casos operados, respectivamente, por um único cirurgião pela técnica de LASIK. Tal diferença provavelmente ocorreu pois o número de pacientes avaliados bem como o de cirurgiões em aprendizado envolvidos nas amostras foram diferentes.

A comparação da eficácia de diferentes microceratótomos tem sido realizada em vários estudos, como o realizado por Binder e col. publicado em $1997^{(5)}$ que compara os microceratótomos ACS (Chiron) e MicroPrecision (Eye Technology) em olhos modelos de Bancos de Olhos. Neste trabalho os autores concluem que diferentes microceratótomos produzem características morfológicas e dimensões do "flap" corneano diferentes daquelas esperadas.

No nosso trabalho podemos dizer que independente do modelo do microceratótomo, as complicações ocorridas são semelhantes.

\section{CONCLUSÃO}

O uso inicial dos microceratótomos automatizados Automated Corneal Shaper ${ }^{\circledR}$ (Chiron) e Carriazo-Barraquer ${ }^{\circledR}$ (Moria) foi relacionado a considerável índice de complicações per e pós-operatórias. Características específicas de cada instrumento ou da técnica cirúrgica estão relacionadas a complicações como Síndrome das Areias do Sahara ou problemas mecânicos do motor do aparelho. Sendo assim, o conhecimento destas alterações e o uso continuado destes instrumentos torna-se necessário para diminuir tais complicações e melhorar o índice de sucesso das cirurgias refrativas.

\section{ABSTRACT}

Purpose: To describe per- and postoperative complications which occurred with the first use of two automated microkeratomes for the performance of LASIK. Methods: Retrospective study of first surgeries performed with two automated microkeratomes. Seventy eyes from 54 patients using Chiron's ${ }^{\circledR}$ microkeratome, Automated Corneal Shaper (ACS) model, from April 1997 to April 1998 and 100 eyes from 82 patients using automated microkeratome Moria ${ }^{\circledR}$ Carriazo-Barraquer (CB), from February 1999 to June 1999. Refractive ablation was performed with the Summit Apex Plus Excimer Laser (193 nm). We evaluated the per- and postoperative complications up to one month of follow-up. Results: Photoablation was not performed in three cases $(4.3 \%)$ using ACS microkeratome and in one case (1\%) using CB microkeratome. Most frequent complications found with ACS were: failure of automated return of microkeratome $(7.1 \%)$, partial keratotomy $(4.3 \%)$, presence of stromal folds (14.3\%), central de-epithelialization (4.3\%). With CB there were: descentered flap (3\%), central desepitheliaza- 
tion (5\%), stromal folds (28\%) and Sahara Sands syndrome $(6 \%)$. Conclusions: Initial use of both microkeratomes was related to important per- and postoperative complications, which did not lead to loss of vision. Clinical knowledge of the alterations which occurred with the use of these instruments and a better experience of their utilization may reduce these complications.

Keywords: Keratomileusis, laser in situ/complications; Keratectomy, photorefractive, excimer laser; Laser surgery; Microsurgery

\section{REFERÊNCIAS}

1. Gimbel HV, Penno EE, van Westenbrugge JA, Ferensowicz M, Furlong MT. Incidence and management of intraoperative and early postoperative complications in 1000 consecutive laser in situ keratomileusis cases. Ophthalmology 1998;105:1839-4, discussion 1847-8.
2. Hayashi S, Braz A, Vasques M, Plut R, Sartori M, Chamon W, et al. Ceratectomia fotorrefrativa com excimer laser de fluoreto de argônio de 193 nm para a correção da mmiopia: estudo clínico. Arq Bras Oftalmol 1997;60:147-51

3. Mori E, Suzuki CK, Allemann N, Schor P, Campos M, Chamon W. Ceratectomia fotorrefrativa associada à ceratotomia lamelar pediculada (LASIK) para correção de miopia e astigmatismo moderados e altos em um serviço universitário. Arq Bras Oftalmol 1998;61:585-9.

4. Carvalho M, Nascimento E, Chamon W, Allemann N, Campos M, Scarpi MJ. LASIK na correção da alta miopia. Arq Bras Oftalmol 1997;60:570-5.

5. Binder PS, Moore M, Lambert RW, Seagrist DM. Comparison of two microkeratome system. J Refract Surg 1997;13:142-53.

6. Lin RT, Maloney RK. Flap complications associated with lamellar refractive surgery. Am J Ophthalmol 1999;127:129-36.

7. Velasco-Martinelli EJ, Tarcha FA. Superior hinge laser in situ keratomileusis. J Refract Surg 1999;15(2 Suppl):S209-11.

8. Kaufman SC, Maitchouk DY, Chiou AG, Beuerman RW. Interface inflammation after laser in situ keratomileusis. Sands of the Sahara syndrome. J Cataract Refract Surg 1998;24:1589-93.

9. Kim HM, Song JS, Han HS, Jung HR. Streptococcal keratitis after myopic laser in situ keratomileusis. Korean J Ophthalmol 1998;12:108-11.

10. Al Reefy M. Bacterial keratitis following laser in situ keratomileusis for hyperopia. J Refract Surg 1999;15(2 Suppl):S216-7.

\section{Encontro da Academia Americana de Oftalmologia}

\section{1 a 14 de Novembro de 2001 \\ New Orleans - Lovisiania - EUA}

INFORMAÇÕES: Meetings \& Exhibits Division

POBox 7424

San Francisco, CA $94120-7424$

e-mail: meetings@aao.org

home page: www.eyenet.org (pode ser acessada

à partir da home page do CBO: www.cbo.com.br) 